\title{
Coal Mine Trackless Rubber Tyred Vehicle Control System Design based on ARM
}

\author{
Yuanbin $\mathrm{Hou}^{1, \mathrm{a}}$, Yong Chen ${ }^{2, \mathrm{~b}}$ \\ ${ }^{1}$ Department of electrical and control engineering, Xi'an University of Science And Technology, \\ Xi'an, 710054, China \\ ${ }^{2}$ Shaanxi coal mine group Shenmu Hong Liulin Mining Co. Ltd., Yulin, 719300, China \\ bemail: 282120890@qq.com
}

Keywords: Safety Monitoring; Coal Mine; Trackless Rubber Tyred Vehicle

\begin{abstract}
This paper for red Liulin coal mine underground complex production environment combined with actual shipped, designed a set based on the arm of the coal mine trackless rubber tyred vehicle inspection control system. System can be detected by the vehicle detector in coal mine underground without trackless rubber tyred vehicle operation (such as: smoke concentration, trackless rubber tyred car battery power, running current, vehicle speed) for real-time detection, and the obtained data is transmitted to the ARM chip of trackless rubber tyred vehicle monitor, through the display monitor module for real-time display, and can be treated to upload data to the center of the monitoring system of the station, so as to realize the information of underground trackless tyred vehicle operating data acquisition and analysis in real-time. If the running state of the vehicle is abnormal, through trackless rubber tyred vehicle monitoring center issued a directive, through the vehicle monitor to change the trackless rubber tyred vehicle running status. If necessary, can also be a short distance through the infrared remote control to change the trackless tyred vehicle running status.
\end{abstract}

\section{Introduction}

Before the eighties of the 20th century, no domestic auxiliary rail transportation research is still blank. Until the early 1990s began the introduction of non rail rubber tyred auxiliary haulage equipment, in actual use, to improve the accessibility to transit and mine full production efficiency is very obvious. From the beginning of the 90 's, a few new coal mines in China to introduce advanced coal mining auxiliary transport equipment. Explosion-proof trackless rubber tyred vehicle products have gradually become domestic and domestic Changzhou scientific research trial manufacture center, Shanxi Coal Machinery Equipment Co., Ltd. the two companies products market possession rate is larger. After many years of development, the main use of the current system, the main KJISA mine locomotive transport monitoring system, KJ41 locomotive monitoring system, KJ221 locomotive transportation monitoring system, the system can be used in the transportation system of the remote control, such as signal machine, switch, etc., to achieve the range of motor vehicle running. With the continuous improvement of the modernization level of coal mining enterprises, the new requirements for the coal mine auxiliary transportation system, especially the rapid development of computer technology, modern control technology, sensor technology and communication technology, can solve many problems that have plagued the development of auxiliary transportation system. According to the characteristics of coal mine auxiliary transport, the function of the auxiliary transportation system in the coal mine is studied, and the development and implementation of safety and efficiency of the auxiliary transportation system has become the direction of the development of coal mine auxiliary transport system.

\section{Analysis of vehicle running and working state identification}

The vehicle identification card fixed in the trackless rubber tyred vehicle, in the center of the system software to establish identification card ID number and vehicle information correspond to 
each other and storage, to ensure the uniqueness of the number of vehicles. Vehicle identification card and card reader is composed of a wireless identification system operating in the $2.4 \mathrm{GHz}$ microwave frequency band, the vehicle identification card is periodically transmitted in accordance with the agreed format encryption ID number. In the receiving area of the reader, the reader receives the microwave signal, and after the low noise amplification, demodulation and verification, the receiving data is determined, the sound, the light prompt, the memory card information and the receiving time, carries on the information.

The vehicle management station received card vehicle location data is collected after immediately of the traffic signal lamp control scheduling, if two refuge roadway between no vehicle, at both ends of the section of the signal lamp through a fixed time to switch status indication to assign sections of powers and avoid the signal lamp Quanhong leads to lower efficiency and signal lamp green exists security risks, as shown in Figure 2 (a) shows, the No. 1 car saw red lights in the refuge chamber wait, 2 car can enter the road. If there is no vehicle in the closed section of the road, the road is in the idle state, and the 1 car will be scheduled, as shown in Figure 2 (b). 1 vehicles into the road, the road was occupied, as shown in Figure 2 (c), when the car will be prohibited from entering the section 2, the signal is no longer switch, you must wait for the car out of the road 1 , road resources are released, 2 car to enter the road. At the same time, the system can be used to control the state of the signal lamp in the center of the ground, and realize the manual operation of the underground vehicle. The operation mode of the above mentioned vehicles is shown in figure 1.

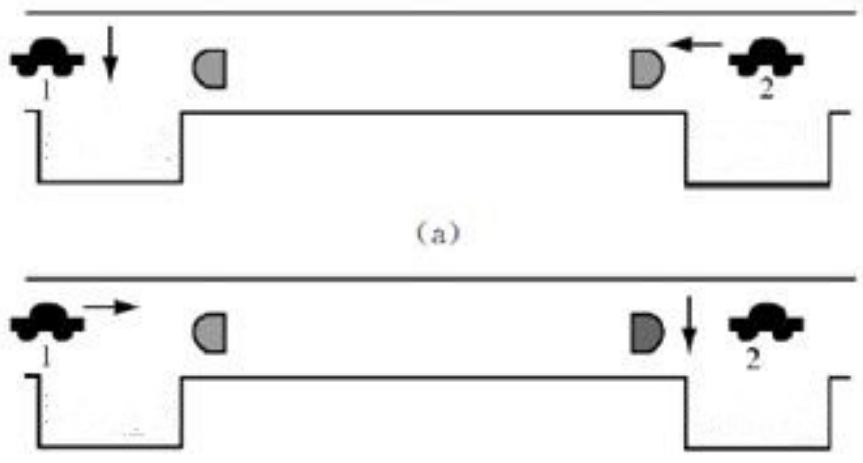

(b)

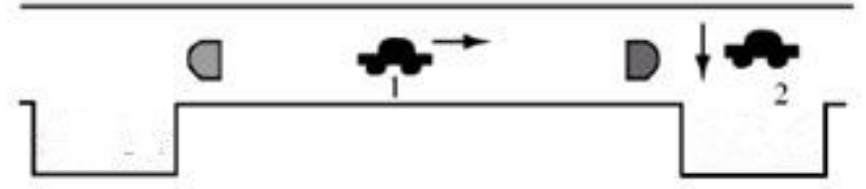

Figure 1 Vehicle traveling direction scheduling management

\section{Working condition identification of vehicle}

The figure 1 rubber tyred vehicle monitor detection module detects smoke signal, battery electric quantity signal, overload current signal and rubber tyred vehicle speed signal sent to figure 1 trackless rubber tyred vehicle hardware monitor arm input port, to tie in with the design of the software to achieve on working condition of the rubber tyred vehicle identification.

\section{Trackless car monitor hardware design}

The main circuit of the vehicle management station main control chip with 32 bit microcontroller system of substation, meet the real-time requirements of rapid control. The processor integrated the ARM7TDMI-S core, with a large capacity of the internal Flash and SRAM, to provide $10 / 100 \mathrm{M}$, bit/s UART, fast Ethernet port, CAN interface, SD card memory interface, such as peripheral interface. The ground monitoring host or local / remote control station initialization parameter settings, substation according to the initialization information acquisition 
corresponding sensor information, corresponding logical algorithm implementation, generating new display state and control the output. Save the station and the center of the ground station to maintain communication and the collected information and perform the control logic to send to the ground a database server. Trackless rubber tyred vehicle monitor hardware components include: CPU module, communication module, memory module, infrared remote control module, display module. No monitor hardware structure of vehicle rail as shown in figure 2.

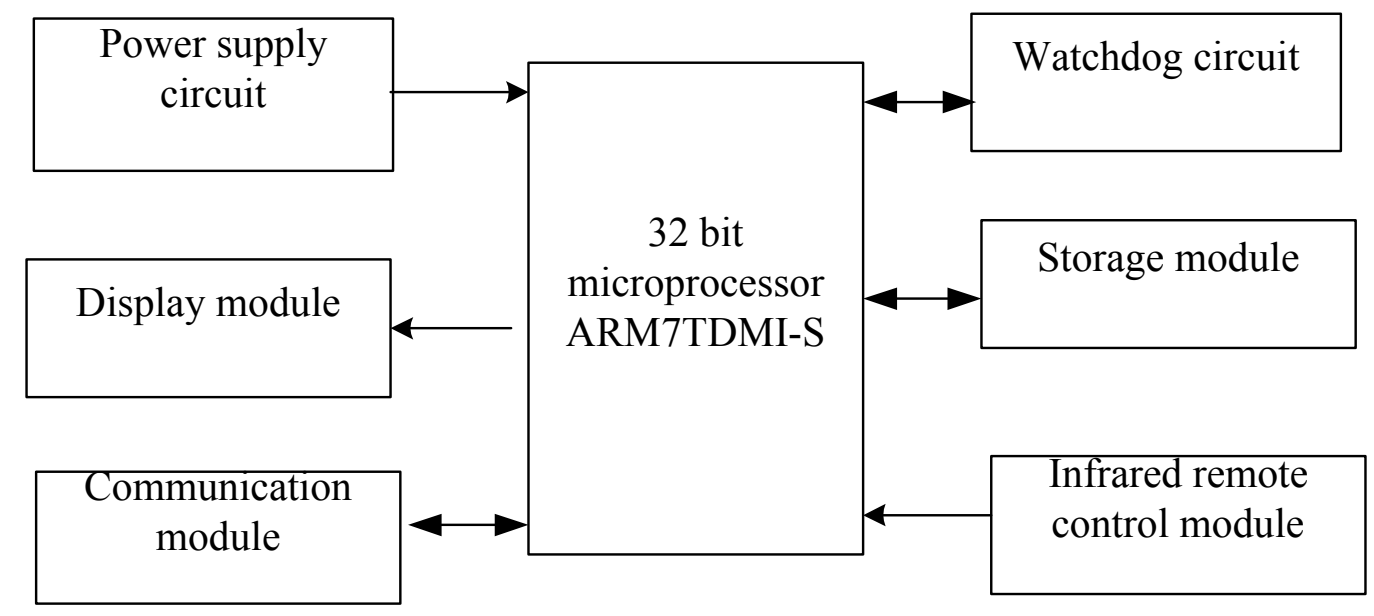

Figure 2 monitor hardware structure of rail vehicle

\section{The design of vehicle detection module monitor}

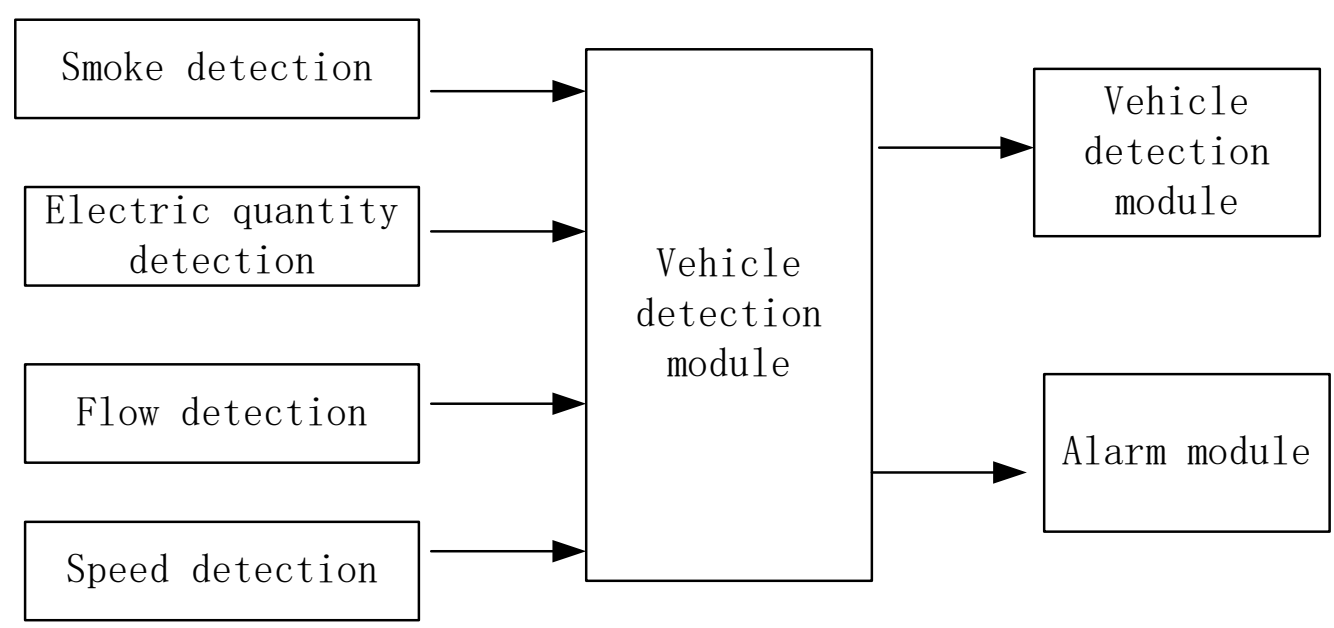

Figure 3 The detection module of rubber tyred vehicle monitor

Figure 3, vehicle monitor detection module is mainly to smoke concentration, trackless rubber tyred car battery power, running current, vehicle driving speed of the four parameters were detected and by vehicle detection module, the detected signal transmission to a trackless rubber tyred vehicle monitor.

\section{System software design}

Trackless rubber tyred vehicle monitoring system software using. Net technology, using oriented object of visual programming tools VC2013 development platform design development, database is SQL Sever 2012, server operating system to Windows 7, communication network adopts 
soket 2.0, dynamic web pages using ASP, ActiveX, java development tools, web service by three layers architecture. System center station software function module as shown in figure 4.

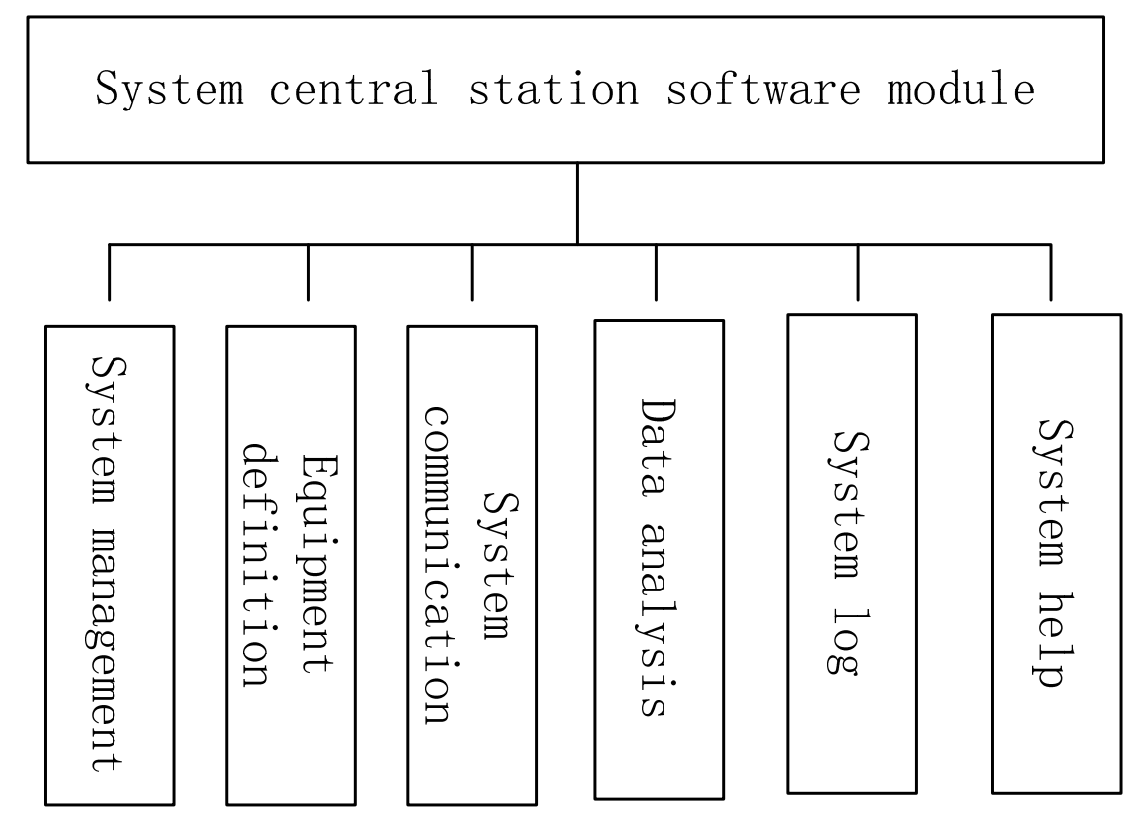

Figure 4 Central station software function module of trackless rubber tyred vehicle

System management module: the main user management, including the user's new, modify, delete, etc.; user rights management; system parameters set functions, such as alarm parameters, database configuration parameters, etc.. Equipment definition module: mainly responsible for the logical definition of access equipment in the system, such as the definition of the vehicle management station, communication links, read card device, signal lamps and other equipment of the logical address, type of equipment, installation position and. Communication module of the system: it mainly realizes the function between the host and the vehicle management station, data interface or network switch data transceiver and the communication protocol analysis. Data analysis module: the main completion of the underground vehicle positioning, trajectory tracking, the current position of the query, the direction of the direction of the road, the traffic command of the development of the auxiliary transport system, many constraints. According to the characteristics of coal mine auxiliary transport, the function of the auxiliary transportation system in the coal mine is studied, and the development and implementation of safety and efficiency of the auxiliary transportation system has become the direction of the development of coal mine auxiliary transport system. Function. System log module which provides in the running process of the system user log, the vehicle management station, read card device, signal lamps and other equipment running status $\log$, communication system, such as $\log$ for system maintenance and fault analysis. 


\section{The software design of trackless vehicle monitor}

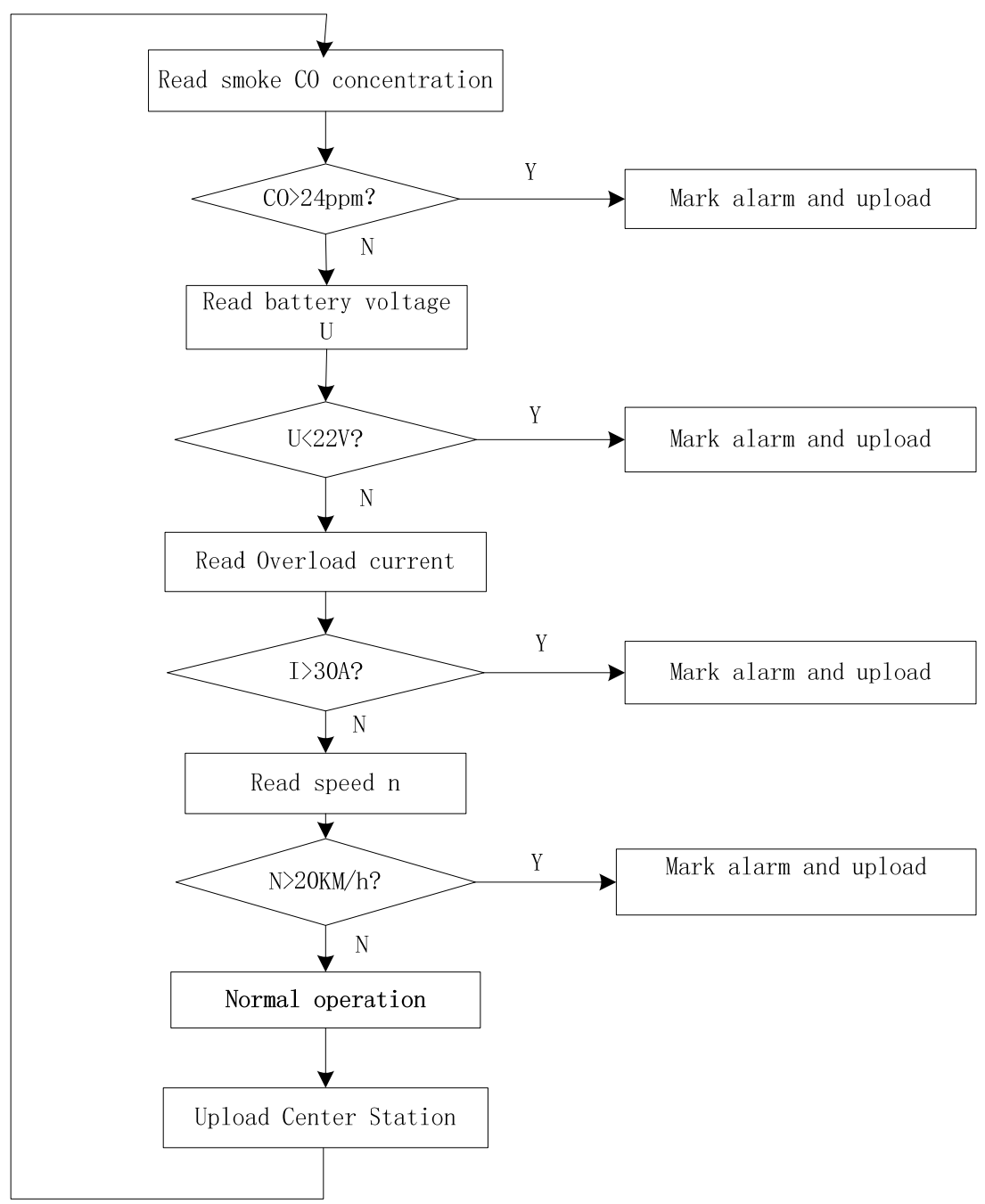

Figure 5 The software flow of trackless vehicle monitor

Firstly, the vehicle monitor is the judgment of the smoke sensor CO concentration is greater than the 24PPm, if less than 24PPm mark alarm and upload, if not less than 24PPm, read overload current value, if greater than 30A mark, alarm and upload, if not more than $30 \mathrm{a}$, reading speed value, if the speed is greater than $20 \mathrm{~km} / \mathrm{h}$, mark, and upload the alarm, if not more than $20 \mathrm{~km} / \mathrm{h}$ show normal running of the rubber tyred locomotive, will be the normal operation of the state values upload to the center of the ground station.

\section{Conclusion}

System of underground non rail rubber tyred vehicle vehicle traveling direction of accurate judgment, and through the signal of moving vehicles for traffic control. The operating condition of the vehicle can be remotely controlled by infrared remote control, and the method of wireless communication is used to realize the fast interaction between the vehicle information and the reliability and real-time performance of vehicle scheduling. The system uses a reliable wireless information exchange technology, which can be used to transmit the information to the ground control center. 


\section{References}

[1] Tian Zhenlin, Li Yaohui. Coal mine underground coal mine auxiliary transport. Coal technology, 2006, (10): 30 - 29

[2] Dai Zhi wow. The status and application of coal mine trackless vehicles. Coal science and technology, 2003, (2): 21 - 24

[3] $\mathrm{Xu} \mathrm{Yi,} \mathrm{Zhu} \mathrm{Kongsheng.} \mathrm{Application} \mathrm{of} \mathrm{trackless} \mathrm{vehicles} \mathrm{in} \mathrm{modern} \mathrm{mine.} \mathrm{Coal} \mathrm{mine}$ modernization, 2003, (2): 15 - 16

[4]Ren Shan, Wang Suiliu, programmable controller in the coal mine motor vehicle transport signal system in the application of Shanxi coal, 2001, (4): 38 - 36

[5] Li Yuliang. Interface technology for locomotive monitoring system. Coal Mine Electromechanical, 2001 (2): 28 -26

[6] Tian Hua. The monitoring system used in coal mine car transport rubber tire [J]. industrial automation, 2012, 38 (9):118-120.

[7] Zhang Liangku, Yao Shaowu. China's coal mine trackless rubber tyred vehicle status and development direction. Sci tech Information Development \& economy, 2011, 28 (9):18-20 